\title{
IRONY AS A MEANS OF CHARACTER DESCRIPTION IN THE WORKS BY N.V. GOGOL
}

\author{
Svetlana S. Vaulina \\ Immanuel Kant Baltic Federal University, Kaliningrad, Russia \\ Elena V. Bulataya \\ Baranovichi State University, Baranovichi, Belarus
}

\begin{abstract}
The article considers irony as a conceptual category of the literary text, that contains author's assessment in the implicit form. The ironic meaning as an integral component of the literary text is an evaluative and emotional way to represent the author's worldview and values. The means of expressing irony in N.V. Gogol's works of different genres (epos, lyrico-epic genre and drama) are determined. The similarities and differences in the author's use of irony expression means in the poem Dead Souls, series of tales Evenings on a Farm near Dikanka, Mirgorod, Petersburg Tales, comedy The Inspector General within the author's ironic character description are determined. The article concludes that genre peculiarities of literary works affect the author's choice of certain means of irony expression. It is not typical of the author to use phraseological units as irony explicators in the genre of the tale; however, these linguistic means frequently verbalize ironical meaning in the drama genre - the comedy The Inspector General. The use of such textual means as author's retreats and comments is not typical due to high plot dynamism and dialogization of the author's narrative being characteristic genre features of the comedy. The article considers the means of irony expression in the author's character description. It is shown that irony is manifested both in the characters' and the author's speech and is aimed at assessing the characters' personality and behavior.
\end{abstract}

Key words: literary text, genre, irony, linguistic means, irony expression means, character description, N. Gogol.

Citation. Vaulina S.S., Bulataya E.V. Irony as a Means of Character Description in the Works by N.V. Gogol. Vestnik Volgogradskogo gosudarstvennogo universiteta. Seriya 2. Yazykoznanie [Science Journal of Volgograd State University. Linguistics], 2019, vol. 18, no. 4, pp. 200-209. (in Russian). DOI: https://doi.org/10.15688/ jvolsu2.2019.4.15

\section{ИРОНИЯ КАК СРЕДСТВО ХАРАКТЕРИСТИКИ ПЕРСОНАЖЕЙ В ПРОИЗВЕДЕНИЯХ Н.В. ГОГОЛЯ}

\section{Светлана Сергеевна Ваулина}

\section{Елена Васильевна Булатая}

Барановичский государственный университет, г. Барановичи, Беларусь

\footnotetext{
Аннотация. В статье рассматривается ирония как концептуальная категория художественного текста, заключающая в себе авторскую оценку в имплицитной форме. Иронический смысл как неотъемлемый компонент художественного текста представляет собой оценочно-эмоциональный способ репрезентации мировоззрения и ценностных установок автора. Определяются средства экспликации иронии в произведениях Н.В. Гоголя различной жанровой принадлежности (эпического, лиро-эпического и драматургического жанров). Устанавливаются сходства и различия в использовании автором средств выражения иронии в по-
} 
эме «Мертвые души», циклах повестей «Вечера на хуторе близ Диканьки», «Миргород», «Петербургские повести», комедии «Ревизор» при авторской иронической характеристике персонажей. Делается вывод о том, что жанровые особенности художественного произведения оказывают влияние на использование автором определенных средств выражения иронии. Для жанра повести нехарактерно использование автором фразеологических единиц как экспликатора иронии, в то время как они достаточно частотны при ироническом смыслообразовании в драматургическом жанре - комедии «Ревизор». При этом для комедии, в силу ряда ее жанровых особенностей (динамизм в развитии сюжета, диалогизация повествования и др.), нетипично использование таких текстовых средств, как авторские отступления и комментарии. Рассмотрение способов актуализации иронии при авторской характеристике гоголевских литературных героев показало, что ирония реализуется как в персонажной, так и в авторской речи и направлена в основном на оценку характера и поведения персонажей.

Ключевые слова: художественный текст, жанр, ирония, языковые средства, средства выражения иронии, характеристика персонажа, Н.В. Гоголь.

Цитирование. Ваулина С. С., Булатая Е. В. Ирония как средство характеристики персонажей в произведениях Н.В. Гоголя // Вестник Волгоградского государственного университета. Серия 2, Языкознание. -2019. - Т. 18, № 4. - С. 200-209. - DOI: https://doi.org/10.15688/jvolsu2.2019.4.15

\section{Введение}

Ирония является объектом исследования в различных гуманитарных науках: философии [Кьеркегор, 1993; Третьякова, 2001; Шлегель, 1980; и др.], эстетике [Каган, 1997; Пивоев, 1982; и др.], психологии [Рубинштейн, 2002; Фрейд, 2014; и др.], литературоведении [Бахтин, 1990; Потебня, 1990; Knox, 1961; и др.], лингвистике [Ермакова, 2014; Петрова, 2011; Походня, 1989; и др.]. Данный факт свидетельствует о многогранном и многостороннем характере категории иронии, что, в свою очередь, объясняет устойчивый исследовательский интерес к ней, а также наличие множества направлений в ее изучении, отражающихся в так называемых теориях иронии.

Примечательно, что, даже если сузить плоскость исследования иронии и рассматривать данную категорию сугубо в рамках ее лингвистической трактовки, можно назвать немалое количество теорий иронии: ирония как элемент идиостиля [Петрова, 2011; и др.], ирония как косвенный речевой акт [Слепцова, 2007; и др.], ирония как способ импликации [Сергиенко, 1995; и др.], ирония как явление прагматики [Гомлешко, 2008; и др.], ирония как когнитивный механизм [Шилихина, 2010; и др.], ирония как имплицитная форма выражения авторской модальности [Ваулина, Булатая, 2017; Ваулина, Булатая, 2019; и др.].

В статье рассматривается ирония как концептуальная категория художественного текста, заключающая в себе авторскую оценку в имплицитной форме.

\section{Функционально-семантическая характеристика иронии в художественном тексте}

Актуальность изучения иронии в пространстве художественного текста определяется прежде всего его смысловым содержанием, которое характеризуется наличием не только явно выраженной, представленной в языковых единицах, но и скрытой информации. При этом важно отметить, что «недостаточность эксплицитного выражения и артикулируемых знаков нисколько не препятствует пониманию; напротив, по мере того как убывает количество слов, выражение становится все более ясным и убедительным» [Балли, 1955, c. 50]. Данный факт объясняется тем, что при распознании имплицитной информации реципиент выступает активным субъектом, прилагает определенные усилия для декодирования и дальнейшей интерпретации скрытого смысла. Это, в свою очередь, и определяет большую действенность неявно представленной информации по сравнению с эксплицитной. Кроме того, в содержании художественного текста именно имплицитный уровень смысла воплощает в себе пространство глубинных авторских замыслов, имеющих для автора произведения первостепенное значение.

Содержащийся в художественном тексте иронический смысл представляет собой критический, а значит, оценочно-эмоциональный способ осмысления действительности писателем. Тем самым ирония в художественном тексте является имплицитной формой 
репрезентации мировоззрения и взглядов автора, то есть авторской модальности. Другими словами, можно, вслед за И.Н. Ивановой, констатировать, что, «воплощая авторский философско-эстетический идеал, ирония в художественном тексте проникает во все его уровни и слои» [Иванова, 2006, с. 6]. Характеризуя иронию в эмоциональном плане, можно согласиться с Н.С. Зинченко, трактующей данную категорию как «языковую игру, основанную на чувственно рассудочном отстранении от объекта, возвышении над ним, соединении несоединимого, новом видении ситуации» [Зинченко, 2016, с. 129]. М.В. Никитин, принимая во внимание оценочный компонент иронии, указывает, что в ситуации, «когда высказывание с положительной оценкой заведомо вступает в конфликт с дотекстовым предзнанием об объекте оценки или с постзнанием о нем, вытекающим из текста» [Никитин, 1988, c. 156], правомерно говорить о наличии иронического смысла. При этом явно представленная автором положительная оценка объекта иронии отодвигается на задний план, а само высказывание воспринимается в качестве «намеренного уничижения объекта оценки в силу того, что у него нет права на заявленный положительный признак» [Никитин, 1988, c. 156]. Следовательно, иронии как концептуальной текстовой категории присуще наличие в ее содержании двух противоположных оценок по отношению к объекту иронии, функционирующих тем не менее в координатах одного и того же текстового сегмента.

Вне сомнения и тот факт, что продуцент художественного произведения создает определенные условия для осмысления и адекватного толкования иронического смысла читателем, а именно важен «учет ситуативного контекста в координатах фоновых знаний, которые в конечном счете создают прецедентный фон, необходимый для декодирования иронии» [Кузнецова, 2014 , с. 130]. Причем маркерами иронии, то есть языковыми единицами, указывающими на присутствие иронического смысла в тексте произведения, выступают как отдельные лексические и фразеологические единицы, так и синтаксические структуры и средства текстового уровня, представленные интертекстуальными явлениями, слож- ными общетекстовыми повторами, авторскими отступлениями и т. д.

\section{Способы иронической характеристики персонажей в разножанровых произведениях Н.В. Гоголя}

Очевидно, что частотность использования иронии автором не зависит от жанра художественного произведения, поскольку ирония передает отношение автора к освещаемой проблеме в целом или персонажам в частности. Вместе с тем все же возникает вопрос о наличии особенностей реализации иронии в определенном жанре художественного текста, важность рассмотрения и сопоставления которых подтверждается общей ролью и местом иронии в системе авторского мировоззрения, поскольку лишь на межжанровом уровне ирония перерастает из обычного авторского приема в «способ видения окружающей действительности» [Кагановская, 1992, с. 15].

Классик русской национальной литературы, выдающийся мастер художественного слова Н.В. Гоголь использует иронию в произведениях различной жанровой направленности. Так, писатель выражает свои ценностные позиции посредством иронии в произведениях эпического жанра - циклах повестей «Петербургские повести», «Вечера на хуторе близ Диканьки», «Миргород»; лиро-эпического жанра - поэме «Мертвые души»; драматургического жанра - комедии «Ревизор». Объектом иронии в гоголевских произведениях выступают, как правило, главные персонажи, ироническая характеристика которых дается автором с помощью оценочного описания различных аспектов их жизни. Причем ирония реализуется в разноплановых, нарочито смоделированных писателем ситуациях в форме как исключительно авторской иронии, так и иронии, передаваемой через речь персонажей.

Рассмотрим на межжанровом уровне особенности реализации иронии в вышеназванных гоголевских произведениях путем анализа способов актуализации иронии в рамках авторской характеристики персонажей.

В поэме «Мертвые души», относящейся к лиро-эпическому жанру, в котором «сюжетное повествование о событиях соединяется с 
эмоционально-медитативными высказываниями повествователя, создающими образ лирического “я”» [Эпштейн, 1987, с. 186], иронический смысл актуализируется с помощью средств различных языковых уровней - от лексического до текстового. Достаточно частотными являются лексические средства, то есть те лексические единицы, которые в результате иронического переосмысления (несовпадения денотативного и контекстуального значений), обусловливают ироническое смыслообразование в контексте. Например, портретная характеристика одного из главных героев поэмы «Мертвые души» - помещика Плюшкина - осуществляется посредством иронического описания автором обстановки его дома:

(1) С середины потолка висела люстра в холстяном мешке, от пыли сделавшаяся похожею на шелковый кокон, в котором сидит червяк (I, c. 148).

В приведенном контексте люстра отождествляется с шелковым коконом и червяком, что иронично представляет как характер персонажа, замкнутого в своем ограниченном пространстве, так и его внешность, подобную червяку, и это закономерно вызывает у читателя негативное отношение к герою.

Невысокую частотность, по сравнению с другими средствами выражения иронии в поэме «Мертвые души», имеют фразеологизмы. При этом в аспекте иронической характеристики героев поэмы примечателен следующий пример:

(2) Право, словно какая-нибудь, не говоря дурного слова, дворняжка, что лежит на сене: и сама не ест сена и другим не дает (I, c. 82).

Ирония содержится в речи одного персонажа - Чичикова, однако ее объектом выступает другой персонаж поэмы - Коробочка. В приведенном контексте автор посредством речи Чичикова описывает поведение и характер Коробочки, используя прием сравнения героини с дворняжкой на сене. Ср. с фразеологизмом собака на сене «кто-либо сам не пользуется чем-либо и другим не дает пользоваться» (Сл. Федорова, с. 638), иронический смысл которого раскрывается с помощью авторского фразеологического окказионализма и сама не ест сена и другим не дает. Та- ким образом, с помощью иронии автор раскрывает скупость героини, ее желание получить побольше выгоды.

Синтаксические средства реализации иронии активно используются Н.В. Гоголем при описании поведения главного героя поэмы «Мертвые души» - Чичикова:

(3) Чтоб вас черт побрал всех, кто выдумал эти балы! - говорил он в сердцах. - Ну, чему сдуру обрадовались? В губернии неурожаи, дороговизна, так вот они за балы! Эк штука: разрядились в бабыи тряпки! Невидаль: что иная навертела на себя тысячу рублей! > .. > Все из обезьянства, все из обезьянства! Что француз в сорок лет такой же ребенок, каким был и в пятнадцать, так вот давай же и мы! <...> (I, с. 211).

Иронический смысл заключен в речи самого персонажа и актуализируется посредством восклицательных предложений. Чичиков, потерпев неудачу с покупкой мертвых душ, возмущается по поводу пышных балов, хотя сам являлся постоянным их гостем и любителем роскоши. Несоответствие эксплицитной информации и имплицитного смысла создает эффект авторской иронии.

Персонажные характеристики с помощью текстовых средств выражения иронии ярко представлены в поэме «Мертвые души» при использовании автором интертекстуальных включений. Например:

(4) Почтмейстер вдался более в философию и читал весьма прилежно, даже по ночам, Юнговы «Ночи» и «Ключ к таинствам натуры» Эккартсгаузена, из которых делал весьма длинные выписки по целым листам, и в чем состояли эти выписки и какого рода они были, это никому не было известно. Впрочем, он был остряк, цветист в словах и любил, как сам выражался, уснастить речь (I, с. 191).

Интертекстуальные включения в форме авторских отсылок к литературным произведениям философской направленности получают яркую ироническую тональность при использовании их в приведенной контекстуальной ситуации. Тот факт, что обычный почтмейстер выписывает из таких произведений сложные для понимания цитаты, представляется весьма абсурдным и раскрывает авторскую ироническую оценку степени образованности 


\section{МАТЕРИАЛЫ И СООБЩЕНИЯ}

мелких чиновников и уровня исполнения ими своих профессиональных обязанностей.

В эпическом жанре гоголевских произведений - «Петербургских повестях», «Вечерах на хуторе близ Диканьки», «Миргороде» ирония актуализируется также с помощью разнообразных языковых маркеров.

Например, авторская ирония, объектом которой выступает герой повести «Нос» Иван Яковлевич, реализуется в результате употребления в рамках одного предложения лексем порядочный «честный, неспособный на низкие поступки» (MAC, т. 3, с. 311) и пьяница, позволяя автору подчеркнуть, что такое качество, как порядочность, отнюдь не присуще данному персонажу:

(5) Иван Яковлевич, как всякий порядочный русский мастеровой, был пьяница страшный (II, с. 38).

Фразеологизмы, создающие динамичность и эмоциональную насыщенность художественного текста, в качестве средства актуализации иронии в проанализированных повестях практически отсутствуют. С одной стороны, это может быть связано с особенностью жанра повести, в целом характеризующегося «степенной» последовательностью в описании событий. С другой стороны, выбор средств иронического смыслопорождения зависит от самой тактики построения сюжета писателем в тех или иных произведениях.

Среди синтаксических средств реализации иронии в гоголевских повестях важное место занимают восклицательные предложения, придающие высокую эмоциональную насыщенность авторской иронической оценке персонажей. Примером может служить отрывок из повести «Ночь перед Рождеством», в котором с иронической насмешкой подчеркивается хитрость и изворотливость героини повести Солохи:

(6) - Это дьяк! - произнес изумившийся более всех Чуб. - Вот тебе на! ай да Солоха! посадить в мешок... То-то, я гляжу, у нее полная хата мешков... Теперь я все знаю: у нее в каждом мешке сидело по два человека. А я думал, что она только мне одному... Вот тебе и Солоха! (III, с. 99).

Текстовые средства экспликации иронии частотно представлены в гоголевских повес- тях общетекстовыми повторами, которые выступают в качестве так называемых смысловых мостиков, соединяющих воедино направления движения мысли писателя. Так, используя синонимический общетекстовый повтор, Н.В. Гоголь с грустной иронией описывает характер главных персонажей повести «Старосветские помещики»:

(7) Нельзя было глядеть без участия на их взаимную любовь. Они никогда не говорили друг другу ты, но всегда вы; вы, Афанасий Иванович; вы, Пульхерия Ивановна» (III, с. 169);

(8) Что бы ни было, но в это время мне казались детскими все наши страсти против этой долгой, медленной, почти бесчувственной привычки (III, c. 184).

Автор иронизирует над изнеженным и, возможно, несколько наигранным отношением персонажей друг к другу, называя их чувства в начале повести взаимной любовью, но делая в конце произведения вывод о существовании в их отношениях лишь долгой, медленной, бесчувственной привычки.

В рамках драматургического жанра в творчестве Н.В. Гоголя особым ироническим колоритом характеризуется комедия «Ревизор», в которой действия и смоделированные автором ситуации наполнены особым комическим эффектом.

В тексте комедии ирония создается лексическими, синтаксическими и текстовыми средствами. При этом наиболее частотными являются лексические средства. Одним из ярких примеров использования лексических единиц для создания ироничного контекста может служить следующий:

(9) Ляпкин-Тяпкин: судья, человек, прочитавший пять или шесть книг, и потому несколько вольнодумен (II, с. 161).

В данном предложении прилагательное вольнодумен как маркер иронии употреблен в одном контексте с причастным оборотом прочитавший пять или шесть книг, и ирония возникает на основе несоответствия семантики лексемы вольнодумен (о судье Ляпкине-Тяпкине), то есть «свободомыслящий» (MAC, т. I, с. 207-208), с так называемой расшифровкой ее контекстного значения - «человек, прочитавший всего несколько книг». Та- 
ким образом автор с иронией характеризует судью как человека, имеющего невысокую образованность и узкий кругозор, но завышенную самооценку.

Более частотно, по сравнению с гоголевскими произведениями лиро-эпического и эпического жанров, в комедии «Ревизор» представлены фразеологические единицы как средство экспликации иронии. Приведем один из примеров их употребления, в котором ироническая характеристика писателем главного героя комедии - Хлестакова - посредством фразеологизма передана через речь самого персонажа:

(10) Х л е с т а к о в. Я люблю поесть. Ведь на то живешь, чтобы срывать цветы удовольствия. Как называлась эта рыба? (II, с. 194).

Механизмом иронического смыслообразования в приведенном примере выступает несоответствие значения фразеологизма срывать изветь удовольствия, то есть «беспечно пользоваться радостями жизни» (Сл. Федорова, с. 650), имеющего иронично-экспрессивную окраску, его идентификации в контексте с желанием вкусно поесть, которое является для Хлестакова одной из важнейших целей в жизни.

Синтаксические экспликаторы иронии представлены в комедии «Ревизор» разнообразным набором маркеров. В рамках персонажной характеристики внимание привлекает использование писателем локальных повторов в целях актуализации иронического смысла. Например, посредством синонимического локального повтора автор скрыто выражает негативную оценку поведения героя комедии - городничего, высмеивая такую черту его характера, как лицемерие. При этом авторская ирония передается через речь самого персонажа:

(11) Г о р о д н и ч и й. У меня в доме есть прекрасная для вас комната, светлая, покойная... <..> Не рассердитесь - ей-Богу, от простоты души предложил. < .. > Не подумайте, чтобы я говорил это из лести; нет, не имею этого порока, от полноты души выражаюсь (II, с. 186-187).

Среди текстовых средств выражения иронии в комедии «Ревизор» важное место занимают интертекстуальные включения. При этом полностью отсутствует такой вид текстовых актуализаторов иронии, как авторские отступления и комментарии, что обусловливается особенностью жанра комедии. Интерес представляет ироничная авторская характеристика главного персонажа комедии Хлестакова:

(12) Ан на Ан др е е в а. Как, вы на коленях? Ах, встаньте, встаньте! здесь пол совсем нечист.

Х л е с т а к о в. <...> Я хочу знать, что такое мне суждено: жизнь или смерть (II, с. 222);

(13) Х л е с т а к о в (схватывая за рукудочь). Анна Андреевна, не противьтесь нашему благополучию, благословите постоянную любовь!

Анна Андреевн а (с изумлением). Таквы B Hee?

Х л е с т а к о в. Решите: жизнь или смерть? (II, c. 223).

Аллюзивная отсылка автора к структуре и стилю знаменитого монолога Гамлета «Быть или не быть» (ср.: жизнь или смерть в речи Хлестакова) способствует возникновению иронического смысла в диалоге между Хлестаковым и Анной Андреевной и выражает негативную авторскую оценку поведения персонажа.

\section{Заключение}

Таким образом, на основании проведенного анализа можно констатировать, что ирония выступает в произведениях Н.В. Гоголя личностной особенностью его манеры и стиля повествования, которая определяет видение мира и базовые ценностные ориентиры писателя и функционирует на межжанровом уровне. Используя разнообразные средства выражения иронии, автор разрушает представленную в языковых единицах положительную оценку, имплицитно подчеркивая отрицательные качества характера персонажей.

Независимо от жанра гоголевских произведений ирония выступает в них средством смыслопостроения и в конечном счете служит раскрытию основной темы авторского текста. Однако в рамках использования маркеров иронического контекста имеются все же некоторые особенности, присущие тому или иному жанру. Так, для повести нехарактерны фразеологические единицы в функции маркеров иронии. В то же время они используются писателем в поэме «Мертвые души», и особенно частотны в драматургическом жанре, 


\section{МАТЕРИАЛЫ И СООБЩЕНИЯ}

представленном в данной статье комедией «Ревизор». При этом для жанра комедии нехарактерно употребление такого текстового средства, как авторские отступления и комментарии, что обусловлено динамичностью построения сюжета и наличием преимущественно персонажной, а не авторской речи. Этот факт свидетельствует о влиянии жанровых характеристик произведения на выбор автором тех или иных средств репрезентации иронии.

Ироническая характеристика персонажей занимает ведущее место в гоголевских произведениях, поскольку каждый из них воплощает определенный образ, посредством которого обрисовываются проблемные аспекты изображаемой эпохи. Ирония направлена на критику прежде всего поведения и образа жизни персонажей и в меньшей степени их внешних недостатков. При этом наряду с иронией в речи персонажей имеет место авторская ирония, представленная в рассуждениях, описаниях и обращениях к читателю.

\section{СПИСОК ЛИТЕРАТУРЫ}

Балли Ш., 1955. Общая лингвистика и вопросы французского языка / пер. с фр. Е. В. и Т. В. Вентцель ; ред., вступ. ст. и примеч. Р. А. Будагова. М. : Изд-во иностр. лит. 416 с.

Бахтин М. М., 1990. Творчество Франсуа Рабле и народная культура средневековья и Ренессанса. М. : Худож. лит. 543 с.

Ваулина С. С., Булатая Е. В., 2017. Текстовые средства экспликации иронии как компонента авторской модальности в произведениях Н.В. Гоголя // Международный научно-исследовательский журнал. № 4-2 (58), ч. 2. С. 20-23. DOI: 10.23670/ IRJ.2017.58.045.

Ваулина С. С., Булатая Е. В., 2019. Механизмы иронического смыслообразования в художественном тексте (на примере повестей Н.В. Гоголя «Вечера на хуторе близ Диканьки») // Научный диалог. № 7. С. 56-69. DOI: 10.24224/22271295-2019-7-56-69.

Гомлешко Б. А., 2008. Прагматические функции иронии в тексте // Вестник Адыгейского государственного университета. Серия 2, Филология и искусствоведение. № 3 (31). С. 11-13.

Ермакова О. П., 2014. Является ли ирония речевым жанром? : (Еще раз о некоторых особенностях иронии) // Жанры речи. № 1-2 (9-10). С. 75-80.
Зинченко Н. С., 2016. Ирония как многоаспектный феномен: методологические основы анализа художественного дискурса // Филологические науки. Вопросы теории и практики. № 3-1 (57), ч. 1. С. $126-130$.

Иванова И. Н., 2006. Типология и эволюция иронии в поэзии русского модернизма : автореф. дис. ... д-ра филол. наук. Ставрополь. 40 с.

Каган М. С., 1997. Эстетика как философская наука. СПб. : Петрополис. 544 с.

Кагановская Е. М., 1992. Ирония как средство создания речевой установки в художественном тексте (на материале произведений Марселя Эме) : автореф. дис. ... канд. филол. наук. Киев. 16 с.

Кузнецова А. В., 2014. Феномен иронии в картине мира литературной личности: лингвориторические стратегии // Лингвориторическая парадигма: теоретические и прикладные аспекты. № 19. С. 128-131.

Кьеркегор С., 1993. О понятии иронии / пер. А. Коськовой // Логос. № 4. С. 176-198.

Никитин М. В., 1988. Основы лингвистической теории значения. М. : Высш. шк. 168 с.

Петрова О. Г., 2011. Типы иронии в художественном тексте: концептуальная и контекстуальная ирония // Известия Саратовского университета. Новая серия. Серия: Филология. Журналистика. Т. 11, № 3. С. 25-30.

Пивоев В. М., 1982. Ирония как эстетическая категория // Философские науки. № 4. С. 54-61.

Потебня А. А., 1990. Из записок по теории словесности // Теоретическая поэтика / сост., вступ. ст., коммент. А. Б. Муратова. М. : Высш. шк. С. $132-319$.

Походня С. И., 1989. Языковые средства и виды реализации иронии. Киев : Наукова думка. 126 с.

Рубинштейн С. Л., 2002. Основы общей психологии. СПб. : Питер. 720 с.

Сергиенко А. В., 1995. Языковые возможности реализации иронии как разновидности импликации в художественных текстах : автореф. дис. ... канд. филол. наук. Саратов. 18 с.

Слепцова М. А., 2007. Интерактивный аспект иронических высказываний в газетном тексте // Известия Российского государственного педагогического университета им. А.И. Герцена. Т 19, № 45 . С. 252-257.

Третьякова Е. Ю., 2001. Ирония в структуре художественного текста // RELGA. № 19 (73). URL: http://www.relga.ru/Environ/WebObjects/tguwww.woa/wa/Main?textid $=443 \&$ level $1=$ main $\&$ level2=articles (дата обращения: 15.08.2019).

Фрейд 3., 2014. Остроумие и его отношение к бессознательному. М. : Азбука-Классика. 288 с.

Шилихина К. М., 2010. Современные теории иронии (Рец. на кн.: Irony in Language and 
Thought : A Cognitive Science Reader / ed. by H. L. Colston and R. W. Gibbs, Jr. New York : Lawrence Erlbaum associates, 2007. - 619 p.) // Вестник Воронежского государственного университета. Серия: Лингвистика и межкультурная коммуникация. № 1. С. 228-230.

Шлегель Ф., 1980. Идеи // Литературные манифесты западноевропейских романтиков / собр. текстов, вступ. ст. и общ. ред. А. С. Дмитриева. М. : Изд-во Моск. ун-та. С. 60-62.

Эпштейн М. Н., 1987. Лиро-эпический жанр // Литературный энциклопедический словарь. М. : Сов. энцикл. С. 186.

Knox N., 1961. The Word Irony and Its Context, 1500 1755. Durham, N. C. : Duke University Press. 258 p.

\section{ИСТОЧНИКИ И СЛОВАРИ}

I - Гоголь Н. В. Мертвые души. М. : Худож. лит., $1972.415 \mathrm{c}$.

II - Гоголь Н. В. Повести. Драматические произведения. Л. : Худож. лит., 1983. 328 с.

III - Гоголь Н. В. Вечера на хуторе близ Диканьки. Миргород. Минск : Народная асвета, 1980. $351 \mathrm{c.}$

$M A C$ - Словарь русского языка : в 4 т. М. : Рус. яз., 1981-1984. $4 \mathrm{~T}$.

Сл. Федорова - Федоров А. И. Фразеологический словарь русского литературного языка. М. : Астрель : АСТ, 2008.878 с.

\section{REFERENCES}

Balli Sh., 1955. Obshchaya lingvistika i voprosy frantsuzskogo yazyka [General Linguistics and French Language Issues]. Moscow, Izd-vo inostrannoy literatury. $416 \mathrm{p}$.

Bakhtin M.M., 1990. Tvorchestvo Fransua Rable $i$ narodnaya kultura srednevekovya $i$ Renessansa [Works of Francois Rabelais and Folk Culture of the Middle Ages and the Renaissance]. Moscow, Khudozhestvennaya literatura Publ. 543 p.

Vaulina S.S., Bulataya E.V., 2017. Tekstovye sredstva eksplikatsii ironii kak komponenta avtorskoy modalnosti v proizvedeniyakh N.V. Gogolya [Textual Means of Explicating Irony as a Component of Author's Modality in N.V. Gogol's Works]. Mezhdunarodnyy nauchnoissledovatelskiy zhurnal [International Research Journal], no. 4-2 (58), part 2, pp. 20-23. DOI: 10.23670/IRJ.2017.58.045.

Vaulina S.S., Bulataya E.V., 2019. Mekhanizmy ironicheskogo smysloobrazovaniya v khudozhestvennom tekste (na primere povestey N.V. Gogolya «Vechera na khutore bliz Dikanki») [Mechanisms of Ironic Meaning Formation in Literary Text (By Example of N.V. Gogol's Novels "Evenings on a Farm near Dikanka")]. Nauchnyy dialog [Scientific Dialogue], no. 7, pp. 56-69. DOI: 10.24224/2227-1295-2019-7-56-69.

Gomleshko B.A., 2008. Pragmaticheskie funktsii ironii v tekste [The Pragmatic Functions of Irony in the Text]. Vestnik Adygeyskogo gosudarstvennogo universiteta. Seriya 2, Filologiya $i$ iskusstvovedenie [Bulletin of Adyghe State University. Series 2: Philology and Art History], no. 3 (31), pp. 11-13.

Ermakova O.P., 2014. Yavlyaetsya li ironiya rechevym zhanrom? (eshche raz o nekotorykh osobennostyakh ironii) [Is Irony a Speech Genre? (Once Again About Some Features of Irony)]. Zhanry rechi [Speech Genres], no. 1-2 (9-10), pp. 75-80.

Zinchenko N.S., 2016. Ironiya kak mnogoaspektnyy fenomen: metodologicheskie osnovy analiza khudozhestvennogo diskursa [Irony as a MultiAspect Phenomenon: The Methodological Foundations of Literary Discourse Analysis]. Filologicheskie nauki. Voprosy teorii i praktiki [Philological Sciences. Issues of Theory and Practice], no. 3-1 (57), part 1, pp. 126-130.

Ivanova I.N., 2006. Tipologiya i evolyutsiya ironii $v$ poezii russkogo modernizma: avtoref. dis. ...dra filol. nauk [Typology and Evolution of Irony in the Poetry of Russian Modernism. Dr. Philol. Sci. Abs. Diss.]. Stavropol. 40 p.

Kagan M.S., 1997. Estetika kak filosofskaya nauka [Aesthetics as a Philosophical Science]. Saint Petersburg, Petropolis Publ. 544 p.

Kaganovskaya E.M., 1992. Ironiya kak sredstvo sozdaniya rechevoy ustanovki $v$ khudozhestvennom tekste (na materiale proizvedeniy Marselya Eme): avtoref. dis. ... kand. filol. nauk [Irony as a Means of Creating a Speech Installation in a Literary Text (Based on the Works of Marcel Aimee). Cand. Philol. Sci. Abs. Diss.]. Kiev. 16 p.

Kuznetsova A.V., 2014. Fenomen ironii v kartine mira literaturnoy lichnosti: lingvoritoricheskie strategii [Irony Phenomenon in Literary Personality's Worldview: Linguistic Rhetorical Strategies]. Lingvoritoricheskaya paradigma: teoreticheskie $i$ prikladnye aspekty, no. 19, pp. 128-131.

Kerkegor S., 1993. O ponyatii ironii [About the Concept of Irony]. Logos, no. 4, pp. 176-198.

Nikitin M.V., 1988. Osnovy lingvisticheskoy teorii znacheniya [Fundamentals of Linguistic Theory of Meaning]. Moscow, Vysshaya shkola Publ. 168 p. 


\section{МАТЕРИАЛЫ И СООБЩЕНИЯ}

Petrova O.G., 2011. Tipy ironii v khudozhestvennom tekste [Types of Irony in Fiction: Conceptual and Contextual Irony]. Izvestiya Saratovskogo universiteta. Novaya seriya. Seriya: Filologiya. Zhurnalistika [Izvestiya of Saratov University. New Series. Series Philology. Journalism], vol. 11, no. 3, pp. 25-30.

Pivoev V.M., 1982. Ironiya kak esteticheskaya kategoriya [Irony as an Aesthetic Category]. Filosofskie nauki [Russian Journal of Philosophical Sciences], no. 4. pp. 54-61.

Potebnya A.A., 1990. Iz zapisok po teorii slovesnosti [From the Notes on the Theory of Literature]. Teoreticheskaya poetika, Moscow, Vysshaya shkola Publ., pp. 132-319.

Pokhodnya S.I., 1989. Yazykovye sredstva $i$ vidy realizatsii ironii [Language Means and Types of Irony Expressing]. Kiev, Navukova dumka Publ. 126 p.

Rubinshteyn S.L., 2002. Osnovy obshchey psikhologii [Fundamentals of General Psychology]. Saint Petersburg, Piter Publ. 720 p.

Sergienko A.V., 1995. Yazykovye vozmozhnosti realizatsii ironii kak raznovidnosti implikatsii $v$ khudozhestvennykh tekstakh): avtoref. dis. ... kand. filol. nauk [Linguistic Possibilities of Implementing Irony as a Kind of Implication in Literary Texts. Cand. Philol. Sci. Abs. Diss.]. Saratov. 18 p.

Sleptsova M.A., 2007. Interaktivnyy aspekt ironicheskikh vyskazyvaniy $\mathrm{v}$ gazetnom tekste [The Interactive Aspect of Ironic Utterances in the Newspaper Text]. Izvestiya Rossiyskogo gosudarstvennogo pedagogicheskogo universiteta im. A.I. Gertsena [Izvestia: Herzen University Journal of Humanities \& Sciences], vol. 19 , no. 45 , pp. 252-257.

Tretyakova E.Yu., 2001. Ironiya v strukture khudozhestvennogo teksta [The Irony in the Structure of the Literary Text]. RELGA, no. 19. URL: http://www.relga.ru/Environ/WebObjects/ tgu-www.woa/wa/Main?textid=443\&level1= main\&level2=articles (accessed 15 August 2019).

Freyd Z., 2014. Ostroumie $i$ ego otnoshenie $k$ bessoznatelnomu [Wit and Its Attitude Towards Unconscious]. Moscow, Azbuka-Klassika Publ. $288 \mathrm{p}$.
Shilikhina K.M., 2010. Sovremennye teorii ironii (Rets. na kn.: Irony in Language and Thought: A Cognitive Science Reader / ed. by H.L. Colston and R.W. Gibbs, Jr. New York: Lawrence Erlbaum Associates, 2007. -619 p.) [Modern Theories of Irony (Book Review: Irony in Language and Thought: A Cognitive Science Reader / ed. by H.L. Colston and R.W. Gibbs, Jr. New York: Lawrence Erlbaum Associates, 2007. - 619 p.). Vestnik Voronezhskogo gosudarstvennogo universiteta. Seriya: Lingvistika i mezhkulturnaya kommunikatsiya [Proceedings of Voronezh State University. Series: Linguistics and Intercultural Communication], no. 1, pp. 228-230.

Shlegel F., 1980. Idei [Ideas]. Dmitriev A.S., ed. Literaturnye manifesty zapadnoevropeyskikh romantikov [Literary Manifests of Western European Romantics]. Moscow, Izd-vo Moskovskogo universiteta, pp. 60-62.

Epshteyn M.N., 1987. Liro-epicheskiy zhanr [Lyro-Epic Genre]. Literaturnyy entsiklopedicheskiy slovar [Literary Encyclopedic Dictionary]. Moscow, Sovetskaya entsyklopediya Publ., p. 186.

Knox N., 1961. The Word Irony and Its Context, 1500 1755. Durham, N. C: Duke University Press. 258 p.

\section{SOURCES AND DICTIONARIES}

Gogol N.V. Mertvye dushi [Dead Souls]. Moscow, Khudozhestvennaya literatura Publ., 1972. $415 \mathrm{p}$.

Gogol N.V. Povesti. Dramaticheskie proizvedeniya [Tales. Dramatic Works]. Leningrad, Khudozhestvennaya literatura Publ., 1983. 328 p.

Gogol N.V. Vechera na khutore bliz Dikanki. Mirgorod [Evenings on a Farm near Dikanka. Mirgorod]. Minsk, Narodnaya asveta Publ., 1980. $351 \mathrm{p}$.

Slovar russkogo yazyka: $v 4 t$. [Dictionary of the Russian Language. In 4 Vols.]. Moscow, Russkiy yazyk Publ., 1981-1984.

Fedorov A.I. Frazeologicheskiy slovar russkogo literaturnogo yazyka [Phraseological Dictionary of the Russian Literary Language]. Moscow, Astrel Publ.; AST Publ., 2008. 878 p. 
C.С. Ваулина, E.В. Булатая. Ирония как средство характеристики персонажей в произведениях Н.В. Гоголя

\section{Information about the Authors}

Svetlana S. Vaulina, Doctor of Sciences (Philology), Professor, Institute for Humanities, Immanuel Kant Baltic Federal University, A. Nevskogo St., 14, 236016 Kaliningrad, Russia, svaulina@mail.ru, https://orcid.org/0000-0001-7109-2836

Elena V. Bulataya, Candidate of Sciences (Philology), Associate Professor, Head of the Department of Theory and Practice of Germanic Languages, Baranovichi State University, Voykova St., 21, 225404 Baranovichi, Belarus, bulataya87@mail.ru, https://orcid.org/0000-0001-7948-5108

\section{Информация об авторах}

Светлана Сергеевна Ваулина, доктор филологических наук, профессор Института гуманитарных наук, Балтийский федеральный университет им. И. Канта, ул. А. Невского, 14, 236016 г. Калининград, Россия, svaulina@mail.ru, https://orcid.org/0000-0001-7109-2836

Елена Васильевна Булатая, кандидат филологических наук, доцент, заведующая кафедрой теории и практики германских языков, Барановичский государственный университет, ул. Войкова, 21, 225404 г. Барановичи, Беларусь, bulataya87@mail.ru, https://orcid.org/0000-0001-7948-5108 